\title{
Impacto da Inclinação Média na Delimitação de Área de Preservação Permanente
}

\author{
Márcio Rocha Francelinoํㅜㅇ José de Arimatea Silva ${ }^{2}$ \\ ${ }^{1}$ Departamento de Solos, Universidade Federal de Viçosa - UFV, Viçosa/MG, Brasil \\ ${ }^{2}$ Departamento de Silvicultura, Universidade Federal Rural do Rio de Janeiro - UFRRJ, Seropédica/RJ, Brasil
}

\begin{abstract}
RESUMO
Mudanças profundas ocorreram no Código Florestal do Brasil em 2012. Soluções políticas superaram critérios científicos, causando perdas consideráveis ao ambiente. Este estudo teve como objetivo avaliar o impacto dos critérios adotados pela Lei 12.651 na delimitação das áreas de preservação permanente (APPs), referente ao terço superior dos morros, numa bacia hidrográfica do Estado do Rio de Janeiro. Foram delimitadas as APPs na Bacia do Rio Cacaria, localizada no município Piraí, considerando-se critérios estabelecidos: na Resolução CONAMA 303 e na Lei 12.651 (Lei de Proteção da Vegetação Nativa-LPVN). Como alternativa, foi proposta uma alteração nessa última lei, com alteração no critério relacionado com a declividade média $\geq 25^{\circ}$ proposta. Estes procedimentos foram desenvolvidos no programa Arcgis 10, utilizando-se o modelo digital de elevação (MDE). Conclui-se que, segundo a LPVN (inclinação média $>25^{\circ}$ ), restaria apenas 1,5\% das APPs de topo de morro que seriam delimitadas utilizando a resolução 303; e, se adotados os mesmos critérios, mas considerando-se a linha de maior declive em vez da declividade média, essa redução nas APPs seria de apenas $22 \%$.
\end{abstract}

Palavras-chave: legislação florestal, topo de morro, geomática.

\section{Impact of Average Slope on the Delimitation of Permanent Preservation Areas}

\begin{abstract}
Profound changes occurred in the Brazilian Forest Code in 2012. Political solutions exceeded scientific criteria, causing considerable losses to the environment. This study aimed to evaluate the impact of the criteria adopted by Law 12651 on the delimitation of permanent preservation areas (APPs) for the upper third of hills of a river basin in the state of Rio de Janeiro. APPs were delimited in the watershed of Cacaria River in the municipality of Pirai, considering the criteria established by CONAMA Resolution 303, Law 12651. Alternatively, a change in Law 12651 was proposed - altering the criteria related to the average slope $\geq 25^{\circ}$ proposed. This procedure was carried out at Arcgis 10 program using a digital elevation model (DEM). We conclude that, according to Law 12651 (average slope $\geq 25^{\circ}$ ), only $1.5 \%$ of APPs on the hill tops delimited using Resolution 303 would be left, and if the same criteria were adopted considering the line of maximum gradient instead of the average slope, this reduction in APPs would be of only $22 \%$.
\end{abstract}

Keywords: forest legislation, hill top, geomatics. 


\section{INTRODUÇÃO}

Ao longo de oito décadas (1934-2012), o Brasil erigiu consistente legislação florestal, com forte identidade temática e vários conceitos técnicos e jurídicos importantes para a proteção, conservação e uso dos recursos florestais. Três momentos marcaram a trajetória desta legislação: a edição do primeiro Código Florestal (Decreto no 23.793, de 23 de janeiro de 1934, conhecido como Código Florestal de 34); a aprovação do novo Código Florestal (Lei no 4.771, de 15 de setembro de 1965); a tumultuada edição da novel norma, que dispõe sobre a proteção da vegetação nativa (Lei no 12.651 , de 25 de maio de 2012, com as alterações promovidas pela Lei $\mathrm{n}^{\circ}$ 12.727, de 17 de outubro de 2012). A despeito de ter pretendido revogar a lei de 1965, a norma de 2012 continua sendo referida como novo Código Florestal, inclusive no sítio da Presidência da República, na área de acesso dedicada à legislação, no tema códigos.

A norma de 1934, erigida sem a participação do Congresso, classificou as florestas em quatro categorias: protetoras, remanescentes, modelo e de rendimento. A de 1965, embora não tenha explicitado, na origem, conceitos e definições em capítulo específico, instituiu, em seu bojo: preservação permanente, reserva legal, exploração florestal e manejo florestal. Parte dos conceitos e definições seria introduzida na lei no ano de 2000 pela Medida Provisória no 1956-50, de 26 de maio, e parte consta da regulamentação feita por decreto (notadamente 5.975/2006) e resoluções Conama (em especial 302/2002, 303/2002 e 369/2006). A lei de 1965 buscou também categorizar, de forma explícita, três unidades de conservação: floresta nacional, parque nacional e reserva biológica. A lei de 2012 trouxe novidades conceituais, a exemplo de área rural consolidada, várzea ou planície de inundação, área verde urbana e crédito de carbono. Ademais, modifica a essência e o alcance de conceitos anteriormente estabelecidos. Como exemplo de modificação na essência, basta verificar o conceito de reserva legal; no tocante ao alcance, topo de morro é um bom exemplo. Os conceitos e definições são apresentados em 27 incisos (um vetado) do artigo $3^{\circ}$ da norma, a qual, neste trabalho, será denominada Lei de Proteção da Vegetação Nativa - LPVN.
Embora o conceito de topo de morro não integre esse conjunto de incisos, este norteia a delimitação das áreas de preservação permanente (APPs) em relevos ondulados, segundo dispõe a Lei ${ }^{\circ} 12.651$ (Brasil, 2012):

Art. $4^{\circ}$ Considera-se Área de Preservação Permanente, em zonas rurais ou urbanas, para os efeitos desta Lei:

$[\ldots]$

IX - no topo de morros, montes, montanhas e serras, com altura mínima de 100 (cem) metros e inclinação média maior que $25^{\circ}$, as áreas delimitadas a partir da curva de nível correspondente a $2 / 3$ (dois terços) da altura mínima da elevação sempre em relação à base, sendo esta definida pelo plano horizontal determinado por planície ou espelho d'água adjacente ou, nos relevos ondulados, pela cota do ponto de sela mais próximo da elevação.

No transcurso das discussões que levaram à revisão do Código de 1965, a Sociedade Brasileira para o Progresso da Ciência - SBPC - alertava sobre a forte ligação, embora não exclusiva, do estado de conservação da vegetação natural nos topos de morros, nas encostas e mesmo nos sopés, com os deslizamentos ocorridos no vale do Rio Itajaí, em 2008, e na zona serrana do Rio de Janeiro, em 2011 (Silva, 2012).

Para Ribeiro et al. (2005), a delimitação das APPs em topos de morros e ao longo das linhas de cumeada requer, necessariamente, que a demarcação seja feita com base nos limites da bacia hidrográfica.

Antes mesmo da conclusão do processo legislativo que resultou na Lei 12.651, Valverde \& Máximo (2012) alertavam que o aumento da restrição para a classificação dos topos de morro como APP (em relação à lei 4.771/65) extinguiria a grande maioria destas áreas, haja vista que, em termos práticos, dificilmente se encontram nos relevos ondulados morros com inclinação média superior a $25^{\circ}$ e altura de 100 metros.

Relativamente às APPs de topo de morros, montes, montanhas e serras, a nova lei introduz duas modificações, quando comparada com a norma regulamentada de 1965: altura mínima e inclinação do terreno. A altura mínima passa a ser 100 metros; no regulamento firmado pela resolução Conama no 303/2002, era 50 metros. A inclinação estava regulamentada nesta mesma resolução como declividade (medida da inclinação) superior a $30 \%$ (aproximadamente $17^{\circ}$ ) na linha de maior 
declividade (Brasil, 2002), enquanto que, na nova lei, a declividade passa a ser a média da feição e com valor superior a $25^{\circ}$.

Este trabalho tem o objetivo de avaliar o impacto dos parâmetros adotados na Lei 12.651 na delimitação das áreas de preservação permanente referente ao terço superior dos morros numa bacia hidrográfica do Estado do Rio de Janeiro.

\section{MATERIAL E MÉTODOS}

\subsection{Caracterização da área de estudo}

A Bacia do Rio Cacaria está localizada no Município de Piraí e se encontra na base da Serra das Araras (Serra do Mar), com uma área de 7.309 ha
(Figura 1). A temperatura média anual da região é de $20,5^{\circ} \mathrm{C}$ e a pluviosidade é de $1.200 \mathrm{~mm} / \mathrm{ano}$ (Dantas, 2001).

A área pertence à unidade geomorfológica das Escarpas das Serras das Araras e Paracambi, composta pelo sistema de relevo Escarpas Serranas Degradadas, sendo drenada pelos principais formadores da Bacia do rio Guandu: Ribeirão das Lajes e Rio Santana (Dantas et al., 2000). Essa unidade abrange a bacia hidrográfica do Rio Cacaria, que está totalmente inserida no município de Piraí, região centro-sul fluminense.

A vegetação original presente é a Floresta Estacional Semidecidual, que foi intensamente alterada ao longo de diferentes ciclos econômicos, sendo o do café o mais expressivo. Atualmente,

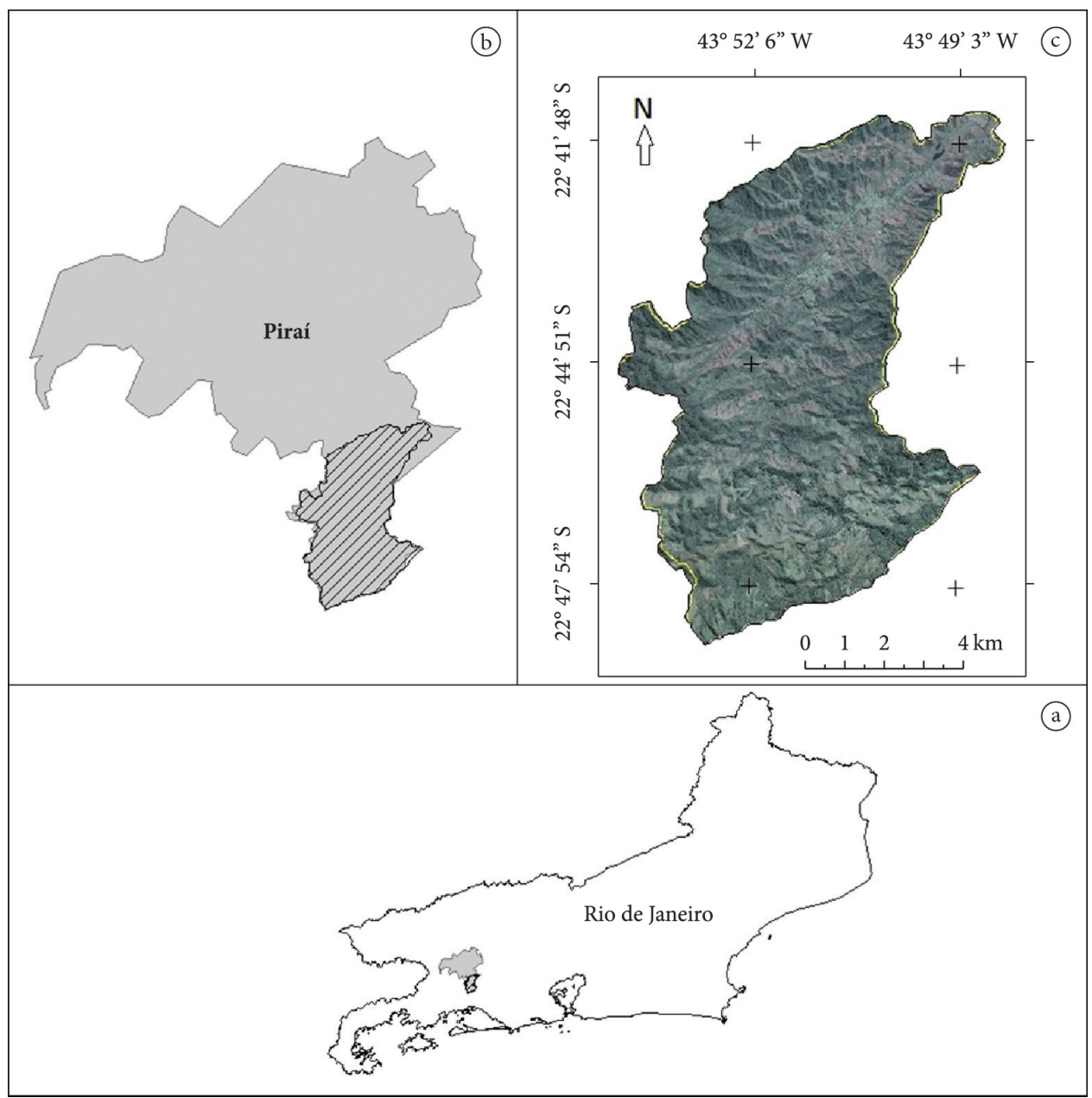

Figura 1. Localização da Bacia do Rio Cacaria.

Figure 1. Localization of the Cacaria River basin. 
podem ser observados fragmentos florestais em diferentes estágios sucessionais oriundos de processos de regeneração natural, os quais ocupam cerca de $60 \%$ da bacia com manchas concentradas principalmente nas maiores altitudes (Lightger, 2013). Os desmatamentos são observados nas bordas da vegetação natural remanescente, de forma geral para aproveitamento agrícola e pastagem, sendo que esta última classe de uso do solo ocupa mais de 35\% da área da bacia (Lightger, 2013).

\subsection{Materiais e softwares utilizados}

Foi utilizado o modelo digital de elevação na escala 1:25.000, disponibilizado gratuitamente na página do Instituto Brasileiro de Geografia e Estatística (www.ibge.gov.br). A resolução espacial deste MDE foi reamostrada de $20 \mathrm{~m}$ para $5 \mathrm{~m}$ através do processo de interpolação presente no programa Arcgis 10, utilizando-se o algoritmo topogrid (topo to raster).

\subsection{Processamento dos dados}

A declividade foi gerada em graus a partir do MDE, utilizando-se ferramenta slope do programa Arcgis 10, e foi reclassificada conforme Embrapa (EMBRAPA, 1995).
Os morros foram delimitados através de três critérios:

1) Resolução Conama no 303/2002: elevação do terreno com cota do topo em relação à base entre 50 (cinquenta) e 300 (trezentos) metros, e encostas com declividade de $17^{\circ}$ na linha de maior declividade - art. $2^{\circ}$, IV (Brasil, 2002);

2) Lei $n^{\circ} 12.651 / 2012$ : elevações com altura mínima de 100 (cem) metros e inclinação média maior do que $25^{\circ}-$ art. $4^{\circ}$, IX (Brasil, 2012);

3) Lei $n^{\circ} 12.651 / 2002$ com suposto: foi adotado o mesmo critério do item 2 , com exceção da declividade, que, em vez ao invés de se considerar a média do morro, foi utilizada como suposto a declividade igual ou maior do que $25^{\circ}$ na linha de maior declividade.

Para delimitar os morros, independentemente da sua altura e declividade, foi utilizada metodologia adaptada de Peluzio et al. (2010), baseada no uso do MDE inverso, utilizando-se o programa Arcgis 10. Para determinação das áreas que atendessem aos critérios das três situações propostas, foram elaborados macros no comando Model Builder (Construtor de modelos) no programa Arcgis 10, para automatizar o processo, utilizando-se o MDE como arquivo de entrada e alterando a altitude e a declividade para cada caso específico. A Figura 2 apresenta um fluxograma geral com as etapas utilizadas nesse procedimento.

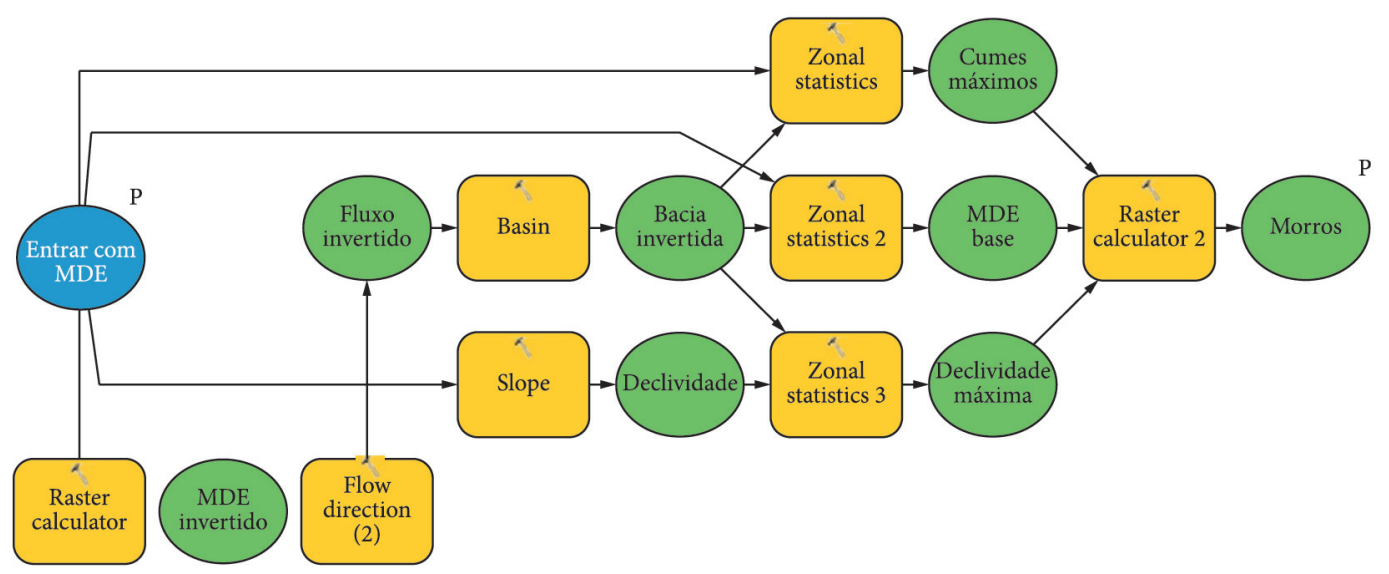

Figura 2. Fluxograma para gerar o limite dos morros. Onde a caixa em azul é o dado de entrada; as caixas em amarelo são os comandos do Arcgis, e as caixas verdes referem-se aos nomes dados aos arquivos de saída. MDE = modelo digital de elevação.

Figure 2. Flowchart to generate the boundary of the hills. Where the blue box is the input data, the boxes in yellow are the Arcgis commands and green boxes refer to the name given to the output files. MDE = digital elevation model. 


\section{RESULTADOS E DISCUSSÃO}

Neste trabalho, não houve distinção entre colina, morro e montanha, pois, segundo Faria (2005), não existe consenso em relação a tais classificações, pois essas definições dependem dos objetivos de cada profissional e do tipo de aplicação. Porém, para a geomorfologia, em geral, considera-se como montanha uma elevação cuja altura em relação à base é maior do que $300 \mathrm{~m}$ e com vertentes de inclinação acentuada (Price, 1991); assim, as elevações que estiverem abaixo deste limite podem ser consideradas morros.

Nesse contexto, o texto da Resolução Conama 303 é o que mais se aproxima desse critério. As modificações trazidas pela Lei 12.651, na concepção de morro, não atenderam a nenhum critério científico, apenas foi o resultado do embate entre interesses de diferentes grupos. No artigo $3^{\circ}$, que traz as definições e conceitos, não consta 'topo de morro' e a própria palavra 'morro' aparece uma única vez na lei. Isso indica que o assunto deverá passar por regulamentação.

A bacia apresenta diferentes padrões geomorfológicos, com desnível altimétrico que varia de $50 \mathrm{~m}$ a mais de $1300 \mathrm{~m}$ de altitude, em que a planície de inundação do Rio Cacaria forma uma extensa área plana próxima do seu exutório, porém com predomínio de relevo forte ondulado em mais da metade de seu território (Tabela 1, Figura 3).

$\mathrm{Na}$ bacia, foram delimitados 210 morros, dos quais somente sete não atenderiam aos critérios da Resolução Conama 303/2012, o que representaria uma área de 6.745,3 ha, que corresponde a mais de $92 \%$ de toda a área da bacia (Figura 4). Vale salientar

Tabela 1. Classes de declividade, conforme Embrapa (1999).

Table 1. Slope classes according to Embrapa (1999).

\begin{tabular}{lc}
\hline \multicolumn{1}{c}{ CLASSE } & ÁREA (\%) \\
\hline Plano & 4,8 \\
\hline Suave ondulado & 5,3 \\
Ondulado & 20,8 \\
\hline Forte ondulado & 54,5 \\
Montanhoso & 14,4 \\
\hline Escarpado & 0,2 \\
\hline
\end{tabular}

que estão sendo consideradas apenas as áreas ocupadas por morros e não pelo seu terço superior, que se enquadraria como área de preservação permanente (APP).

Quando se considera a Lei 12.651/2012, somente três morros atenderiam aos critérios para APP, o que representaria apenas 3\% da área total da bacia (Figura 5). Isso se deve não só ao fato de a altura mínima ter passado de $50 \mathrm{~m}$ para $100 \mathrm{~m}$ e nem do novo nível de referência ser o ponto de sela mais próximo do cume de morros vizinhos, mas principalmente à necessidade de essas feições terem de apresentar declividade média das inclinações superior a $25^{\circ}$. Vale salientar que esse novo critério declividade média do morro - somente é viável de ser obtido utilizando-se, principalmente, ferramentas de geoprocessamento, mais especificamente os sistemas de informações geográficas, o que exigirá pessoal especializado no uso dessas técnicas.

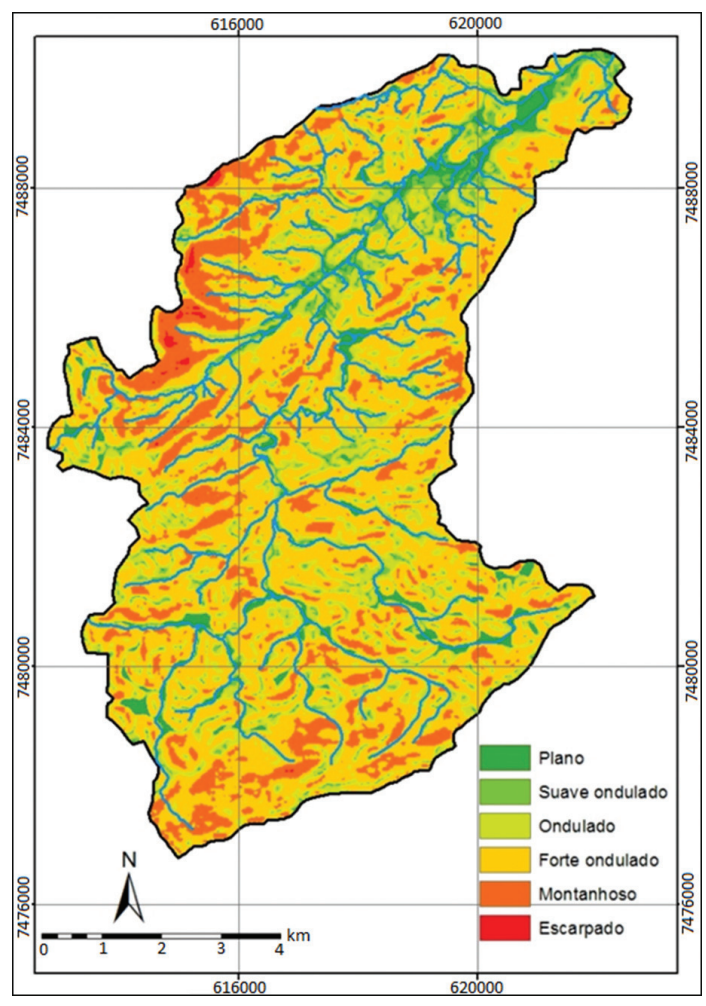

Figura 3. Classes de declividade na Bacia do Rio Cacaria, Piraí-RJ.

Figure 3. Slope classes in the Cacaria River basin, PiraíRJ. 


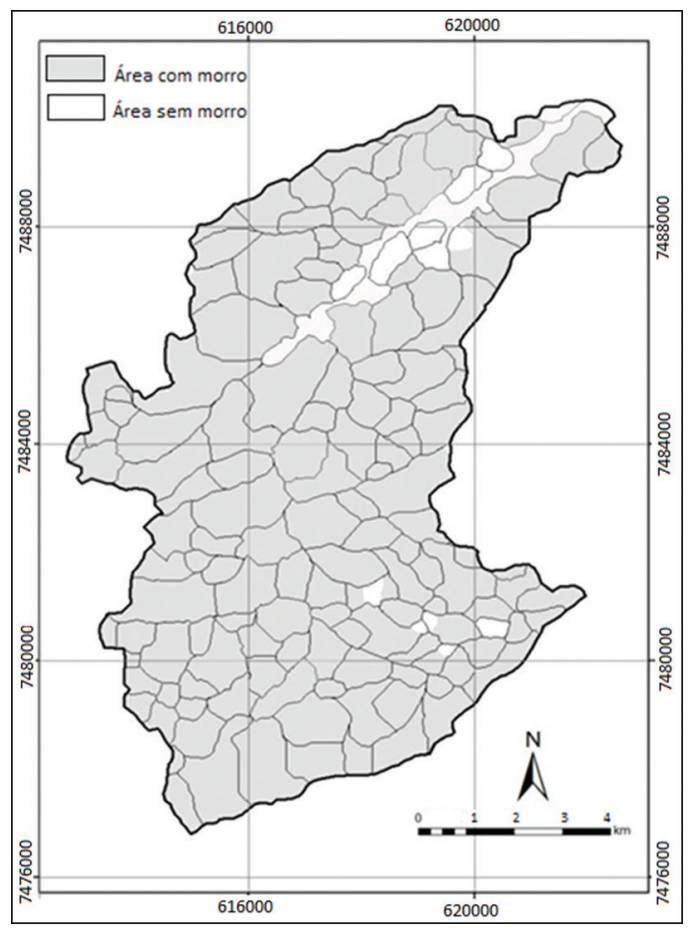

Figura 4. Morros que atenderiam aos critérios contidos na Resolução CONAMA 303/2002.

Figure 4. Hills that would meet the criteria contained in CONAMA Resolution 303/2002.

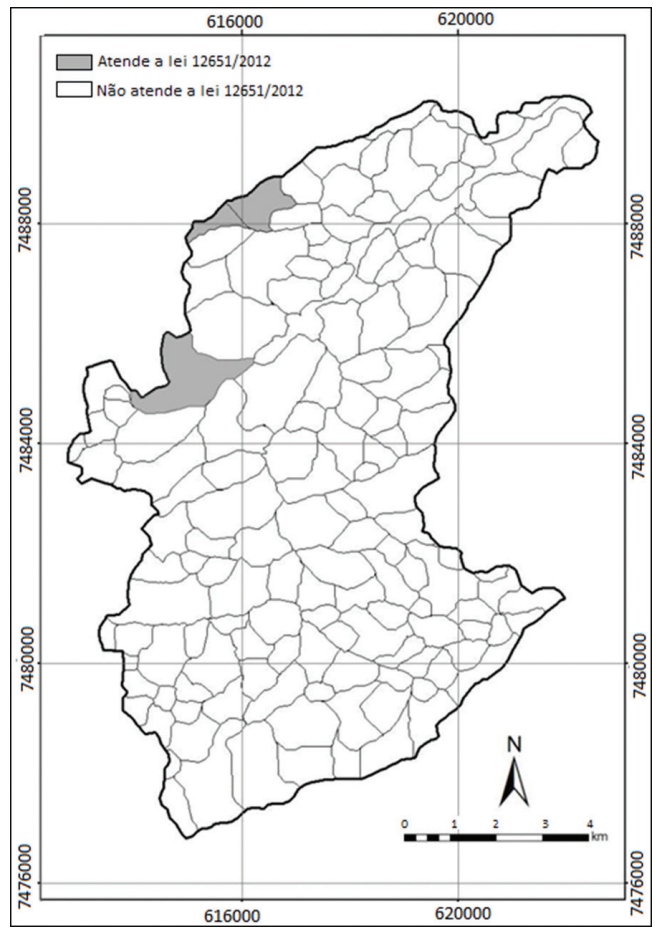

Figura 5. Morros (em cinza) que atenderiam aos critérios da Lei 12.651/2012.

Figure 5. Hills (in gray) that would meet the criteria of Law 12.651/2012.
Porém, caso fosse eliminada a exigência da inclinação média superior a $25^{\circ}$ e se assumisse apenas a linha de maior declive - considerando o mesmo valor máximo de $25^{\circ}$, em vez (ao invés dos $17^{\circ}$-, mesmo mantendo a altura mínima de $100 \mathrm{~m}$, apenas 49 morros não atenderiam aos critérios, fazendo com que a redução dessa categoria de APP fosse bem menor. Na simulação realizada, verificou-se que a área com morros cobre mais de $70 \%$ da bacia (Figura 6).

Em relação à delimitação dos terços superiores dos morros que atenderam aos critérios das três situações consideradas neste estudo, as áreas dessa categoria de APP apresentam valores que variam de $0,5 \%$ a mais de $30 \%$ do território da bacia, conforme pode ser observado na Tabela 2 e nas Figuras 7a, 7b e 7c.

Considerados somente os parâmetros da lei 12.651/2012, as áreas delimitadas de APP topo de morro somariam 36 ha, o que representa cerca de $0,5 \%$ da área total da bacia. Adotado o parâmetro (proposto) de declividade máxima superior a $25^{\circ}$, esse valor seria de 1.795 ha, o que representa 500 ha a menos do que a antiga norma - CONAMA, n 303.

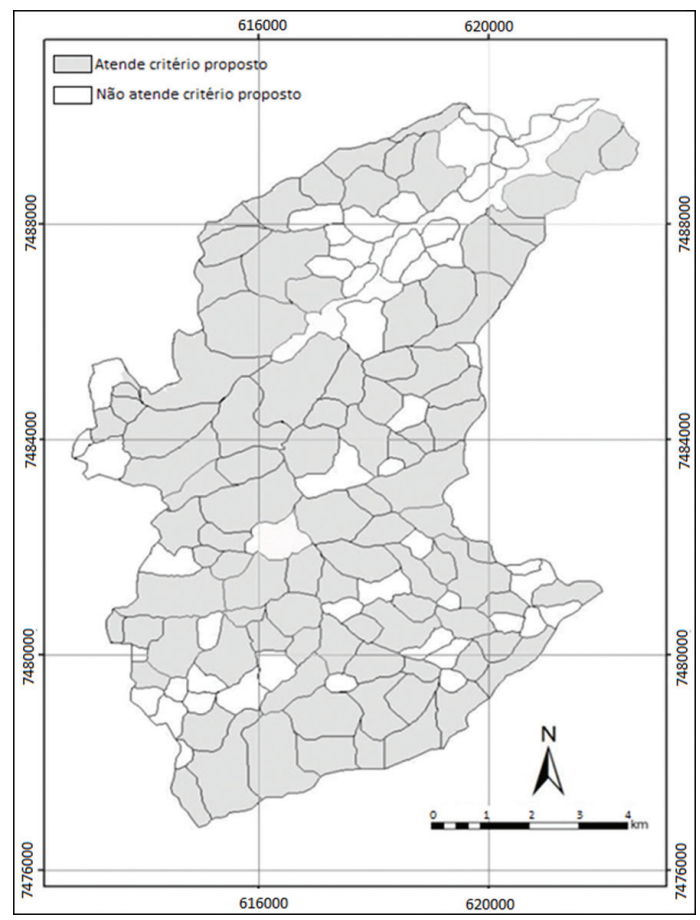

Figura 6. Morros que atenderiam aos critérios da Lei $12.651 / 2012$ com suposto da declividade máxima de $25^{\circ}$. Figure 6. Hills that would meet the criteria of Law $12.651 / 2012$ with the supposed maximum slope of $25^{\circ}$. 
Tabela 2. APPs de topo de morro da Bacia do Rio Cacaria obtidas por diferentes métodos.

Table 2. APPs top of the hill in the watershed of Cacaria river obtained by different methods.

\begin{tabular}{lccc} 
& Método & Área (ha) & Área (\%) \\
Resolução CONAMA 303/2002 & 2.295 & 31,4 \\
Lei $12.651 / 2012$ & 36 & 0,5 \\
Lei 12.651 modificada & 1.795 & 24,5 \\
\hline
\end{tabular}
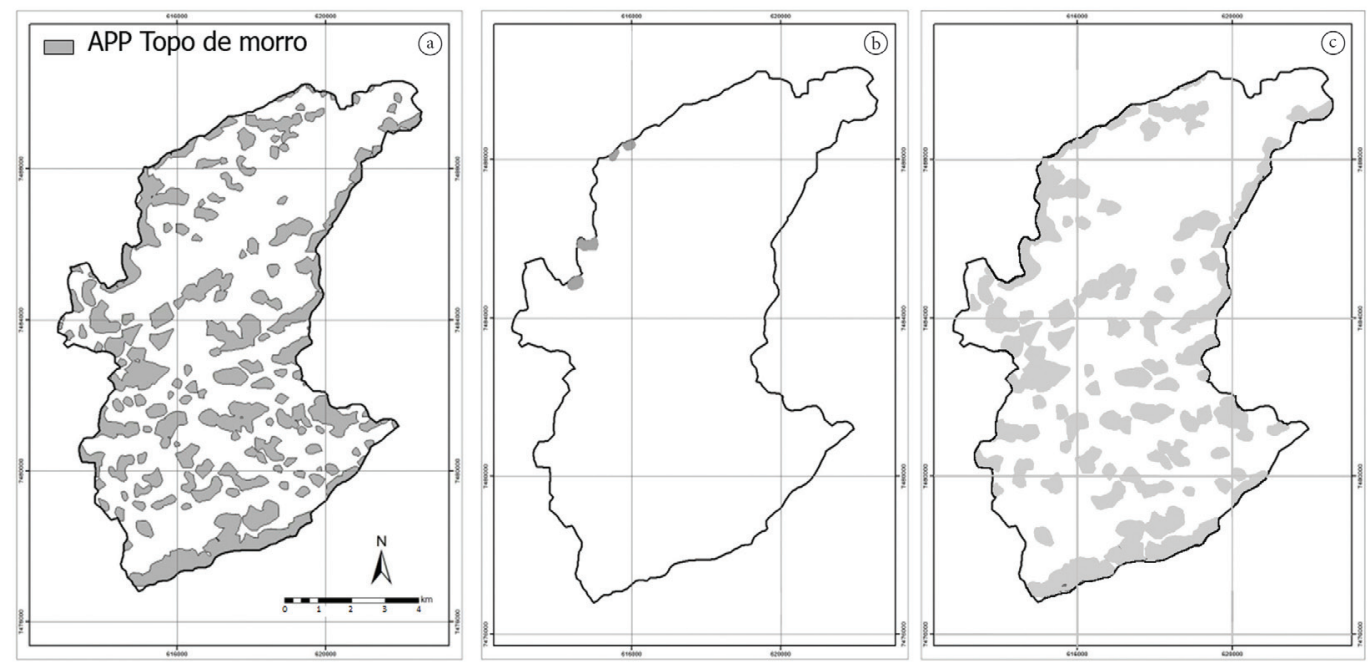

Figura 7. (a) APPs de topo de morro conforme resolução CONAMA 303/2002; (b) Conforme a Lei 12.651/2012, e (c) Conforme Lei 12.651/2012 modificada com proposta.

Figure 7. (a) APPs top of the hill as CONAMA Resolution 303/2002, (b) According to Law 12.651/2012, and (c) According to modified Law 12.651/2012.

Outro fator que deve ser considerado em relação ao mapeamento de APPs é a escala. Valle (2012), estudando o efeito desse parâmetro na delimitação do terço superior de morros em propriedades rurais no médio vale do Rio Paraíba, encontrou diferenças de áreas de até $22 \%$ quando comparou o uso de escalas de 1:5.000 e 1:50.000.

\section{CONCLUSÕES}

A aplicação do critério "inclinação média superior a $25^{\circ}$, , adotado na Lei 12.651 , representou, no caso estudado, a eliminação de quase a totalidade das APPs de topo de morro, restando apenas 1,5\% da área que seria delimitada utilizando-se a resolução CONAMA 303/2002.

Caso fosse adotado na lei o termo "declividade igual ou superior a $25^{\circ}$ na linha de maior declividade", mesmo mantendo o valor de altura mínima de 100 $\mathrm{m}$, a redução da área dessa categoria de APP seria de aproximadamente $22 \%$, em relação aos critérios anteriores (resolução CONAMA 303).

\section{STATUS DA SUBMISSÃO}

Recebido: 3 out., 2013

Aceito: 10 jun., 2014

Publicado: 21 nov., 2014

\section{AUTOR(ES) PARA CORRESPONDÊNCIA}

\section{Márcio Rocha Francelino}

Departamento de Solos, Universidade Federal de Viçosa - UFV, CEP 36570000, Viçosa, MG, Brasil e-mail: marcio.francelino@gmail.com

\section{REFERÊNCIAS}

Brasil. Ministério do Meio Ambiente. Conselho Nacional do Meio Ambiente - CONAMA. Resolução n ${ }^{\circ}$ 303, de 20 de março de 2002. Dispõe sobre parâmetros, 
definições e limites de Áreas de Preservação Permanente. Diário Oficial da União, Brasília, DF (2002 maio 5).

Brasil. Lei $\mathrm{n}^{\circ}$ 12.651, de 25 de maio de 2012. Diário Oficial da União, Brasília, DF (2012 maio 28). [cited 2013 Jan. 22] Available from: http://www.planalto.gov. br/ccivil_03/_Ato2011-2014/2012/Lei/L12651.htm.

Dantas ME, Shinzato E, Medina AIM, Silva CR, Pimentel J, Lumbreras JF et al. Diagnóstico Geoambiental do Estado do Rio de Janeiro. Brasília: CPRM. Serviço Geológico do Brasil; 2000.

Dantas ME. Mapa geomorfológico do Estado do Rio de Janeiro. Brasília: CPRM; 2001. PMCid:PMC1724135

Empresa Brasileira de Pesquisa Agropecuária EMBRAPA. Procedimentos normativos de levantamentos pedológicos: normas em uso pelo SNLCS. Brasília: Serviço de Produção de Informação; 1995.

Empresa Brasileira de Pesquisa Agropecuária EMBRAPA. Sistema brasileiro de classificação de solos. Brasília: Serviço de Produção de Informação; 1999. 412 p.

Faria AP. Classificação de montanhas pela altura. Revista Brasileira de Geomorfologia 2005; 6(2): 21-28.

Lightger. Adequação ambiental de propriedades rurais na bacia do rio Cacaria, Piraí, RJ: projeto PCH Lightger. Paracambi; 2013. Relatório técnico.
Peluzio TMO, Santos AR, Fiedler NC. Mapeamento de áreas de preservação permanente no Arcgis 9.3. Alegre: CAUFES; 2010.

Price LW. Mountains and man: a study of process and environment. Berkeley: University of California Press; 1991.

Ribeiro CAAS, Soares VP, Oliveira MAS, Gleriani JM. O desafio da delimitação da área de preservação permanente. Árvore 2005; 29(2): 203-212.

Silva JAA. O Código Florestal e a ciência: contribuições para o diálogo. 2. ed. São Paulo: SBPC; 2012.

Valle DF. Avaliação das limitações técnicas e custos associados da delimitação das áreas de preservação permanente em propriedades rurais do médio vale do Paraíba [monografia]. Seropédica: Instituto de Florestas, Universidade Federal Rural do Rio de Janeiro; 2012.

Valverde RN, Máximo PS. Novo código florestal: estudo comparativo entre a redação do Projeto de Lei 1.876/99 aprovado na Câmara dos Deputados e as emendas propostas pelo Senado. Viçosa; 2012. [cited 2013 Mar. 25] Available from: http://www.ciflorestas. com.br/arquivos/d_d_d_1326.pdf. 